\title{
The Waveguide Structure Based on the Polymer SU8 on a $\mathrm{SiO}_{2} / \mathrm{Si}$ Substrate
}

\author{
K. GuT* AND S. DREWNIAK \\ Department of Optoelectronics, Silesian University of Technology, Akademicka 2a, 44-100 Gliwice, Poland \\ The paper deals with considerations concerning planar waveguide structures, in which the polymer SU8 is \\ used as the waveguide layer. The results of numerical calculations of the distribution of the field concerning \\ structures of various thicknesses have been presented, and photos taken in the course of investigating the surface \\ by means of a microscope of atomic forces. The results of calculations of sensitivity in relation to the refractive \\ index of the cover layer at various thicknesses of the layer have been presented, too.
}

PACS: 42.25.Hz, 42.25.-p, 42.70.-a, 42.82.Et, 68.35.Ct

\section{Introduction}

Planar waveguide structures may be obtained by means of many techniques, among others by ion exchange in glass, chemical deposition of the layer from the gaseous phase applying plasma (plasma enhanced chemical vapour deposition, PECVD), magnetron sputtering or the formation of thin polymer layers by spin coating [1-18]. In the investigations dealt with in this paper the waveguide structures were obtained by spin coating. As the waveguide layers the polymer SU8 was applied, as the substrate a silicon plate with an $\mathrm{SiO}_{2}$ layer, and as a cover in this structure water was used. On the subsequent substrates the polymer was swirled at various velocities the polymer SU8 was applied because of its high refractive index and good adhesion to the substrate [13]. In numerical analyses the following values of the refractive indices were assumed: $n_{\mathrm{SU} 8}=1.592[14], n_{\mathrm{S}}=1.46$ (refractive index of the substrate-silicon dioxide), and $n_{\mathrm{C}}=1.33$ (refractive index of the cover). In the calculations the thickness of the waveguide layer was varied, whereas the length of the wave of light was assumed as $\lambda=0.633 \mu \mathrm{m}$.

\section{Determination of the thickness of the SU8 layer}

In order to determine the thickness of the SU8 layer a waveguide of the type rib was produced. The obtained structures were tested by means of the microscope of atomic forces AFM from the firm NT-MDT (model NTEGRA Prima). Measurements were carried out in the semicontact mode, applying a HA_NC needle. Figures 1-4 illustrate the topography of selected surfaces, obtained at various velocities of spinning the polymer. Figures 5 and 6 show exemplary cross-sections of these structures. Table presents the velocity of spinning of the photoresist and also the corresponding thicknesses of the layer.

\footnotetext{
* corresponding author; e-mail: kgut@polsl.pl
}

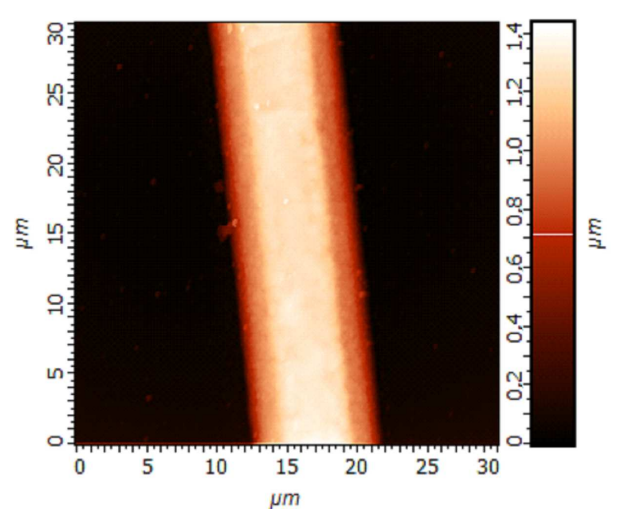

Fig. 1. Velocity of spinning - 3000 rotations per minute.

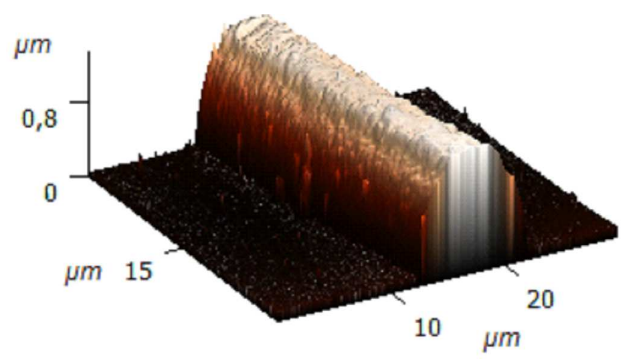

Fig. 2. Velocity of spinning - 3000 rotations per minute.

\section{Analysis of the sensitivity of planar waveguides}

If the planar waveguide is applied as evanescent wave sensors and monitors changes of the refractive index of the cover, an important parameter is the sensitivity $S\left\{n_{\mathrm{C}}\right\}$. It determines changes of the effective refractive index $N_{\text {eff }}$ caused by changes of the values of the refractive index of the cover $n_{\mathrm{C}}$ : 


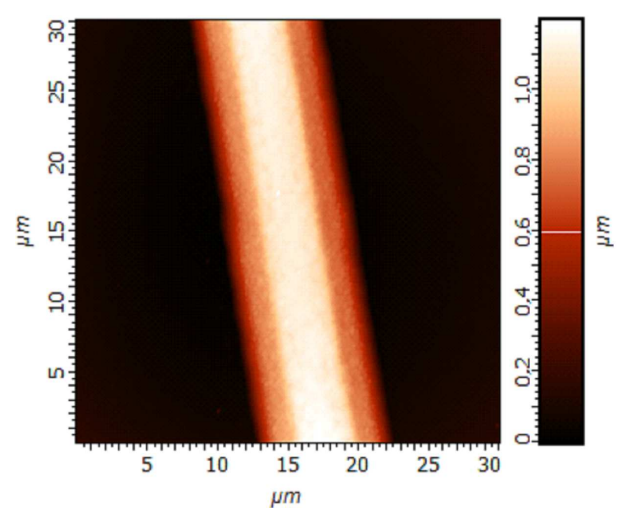

Fig. 3. Velocity of spinning - 4000 rotations per minute.

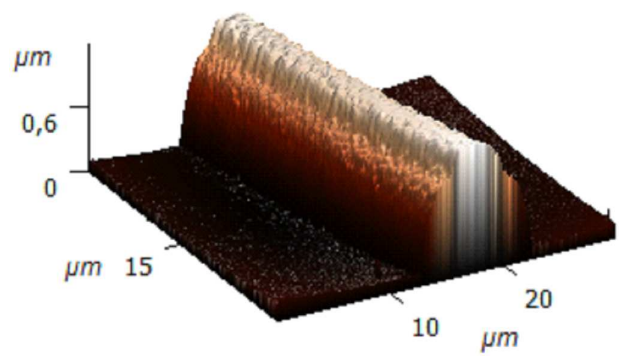

Fig. 4. Velocity of spinning - 4000 rotations per minute.

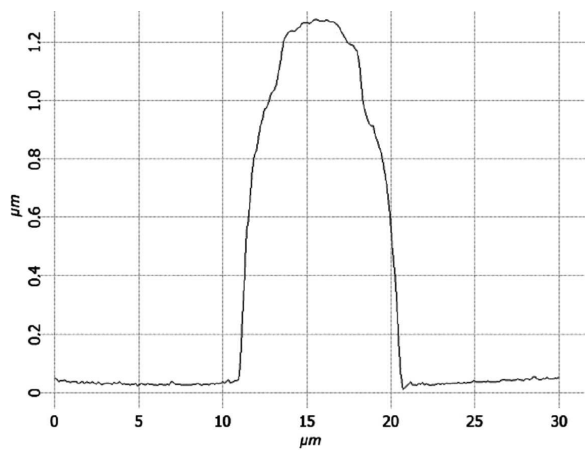

Fig. 5. 3000 rotations per minute - profile of the obtained structure.

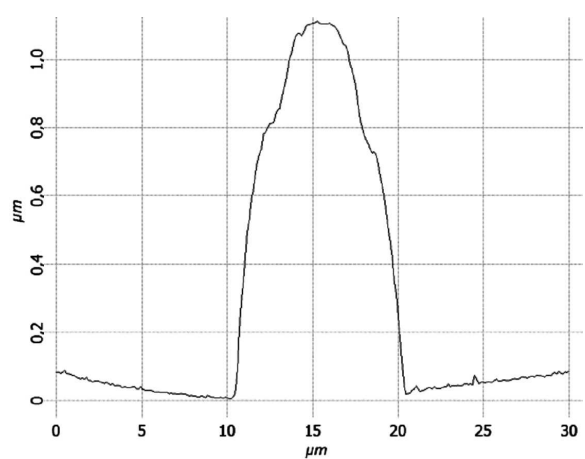

Fig. 6. 4000 rotations per minute - profile of the obtained structure.
TABLE

Velocity of spinning of photoresist and corresponding thicknesses of the obtained SU8 layer.

\begin{tabular}{c|c}
\hline \hline $\begin{array}{c}\text { Velocity of spinning } \\
\text { of photoresist }\end{array}$ & $\begin{array}{c}\text { Thicknesses of the } \\
\text { obtained SU8 layer } \\
d_{\text {SU8 }}[\mu \mathrm{m}]\end{array}$ \\
\hline [rotations per minute] & 0.90 \\
5000 & 1.10 \\
3000 & 1.25 \\
2000 & 1.50
\end{tabular}

$$
S\left\{n_{\mathrm{C}}\right\}=\frac{\partial N_{\mathrm{eff}}}{\partial n_{\mathrm{C}}} .
$$

The effective refractive indices $N_{\text {eff }}$ concerning various thicknesses of the SU8 layer (Fig. 7) were calculated making use of the Optivave software. Knowing the $N_{\text {eff }}$ values, the sensitivity $S\left\{n_{\mathrm{C}}\right\}$ in relation to the cover layer was calculated by means of the formula 1 taken over from Ref. [19]:

$$
S\left\{n_{\mathrm{C}}\right\}=\frac{n_{\mathrm{C}}}{N_{\mathrm{eff}}}\left(\frac{n_{\mathrm{SU} 8}^{2}-N_{\mathrm{eff}}^{2}}{n_{\mathrm{SU} 8}^{2}-n_{\mathrm{C}}^{2}}\right) \frac{\Delta z_{\mathrm{C}}}{d_{\mathrm{eff}}}\left(\frac{2 N_{\mathrm{eff}}^{2}}{n_{\mathrm{C}}^{2}}-1\right)^{\rho},
$$

where

$$
\begin{aligned}
& d_{\mathrm{eff}}=d_{\mathrm{SU} 8}+\sum_{J=\mathrm{S}, \mathrm{C}} \Delta z_{J}, \\
& \Delta z_{J}=\frac{1-\rho}{k\left(N_{\mathrm{eff}}^{2}-n_{J}^{2}\right)^{0.5}} \\
& +\frac{\rho\left[\left(\frac{N_{\mathrm{eff}}}{n_{\mathrm{SU} 8}}\right)^{2}+\left(\frac{N_{\mathrm{eff}}}{n_{J}}\right)^{2}-1\right]^{-1}}{k\left(N_{\mathrm{eff}}^{2}-n_{J}^{2}\right)^{0.5}}, \\
& k=\frac{2 \pi}{\lambda} .
\end{aligned}
$$

In the case of TE polarization the parameter $\rho$ is equal to 0 (for TM polarization the parameter $\rho$ is equal to 1 ). The results of the calculations have been gathered in Fig. 8. It ought to be stressed that by choosing the proper adequate thickness of the waveguide layer it is possible to influence the sensitivity of the obtained structure. The vertical lines in the diagrams indicate the thicknesses of the obtained structures.

A more detailed analysis was carried out concerning planar structures whose thicknesses of the waveguide layer amounted to $0.90 \mu \mathrm{m}, 1.1 \mu \mathrm{m}, 1.25 \mu \mathrm{m}$ and $1.50 \mu \mathrm{m}$. The distribution of the refractive index of the considered structures has been presented in Fig. 9, and Figs. 10-17 illustrate the distribution of the mode field (taking into account the type of polarization). 


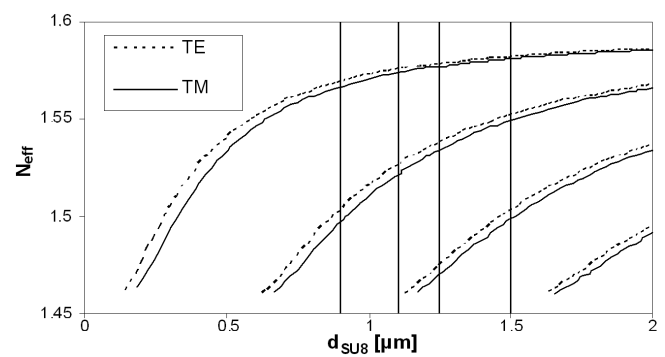

Fig. 7. Effective refractive index $N_{\text {eff }}$ as a function of the thickness of the waveguide layer $d_{\mathrm{SU} 8}$.

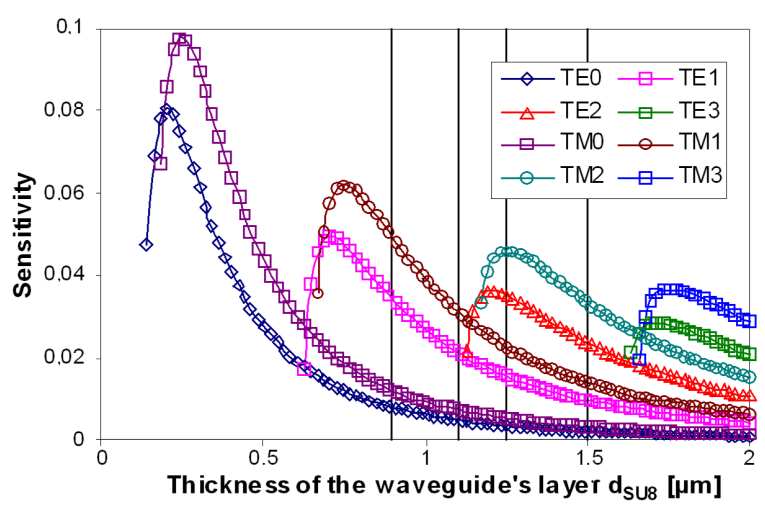

Fig. 8. Sensitivity $S\left\{n_{\mathrm{C}}\right\}$ in relation to the cover layer as a function of the thickness of the waveguide layer $d_{\mathrm{SU} 8}$.

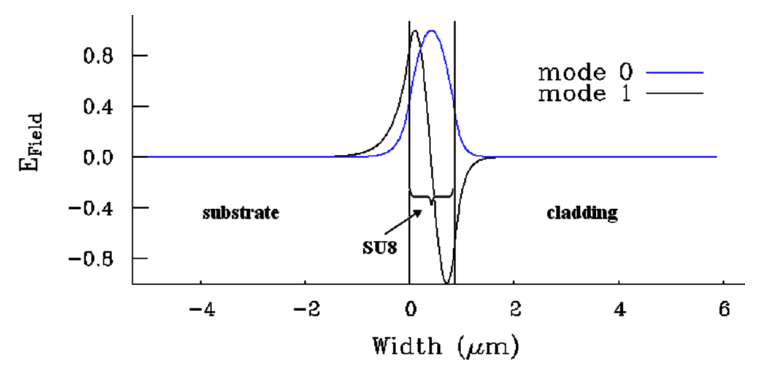

Fig. 9. Distribution of the field of TE polarization at a thickness of the waveguide layer $d_{\mathrm{SU} 8}=0.90 \mu \mathrm{m}$.

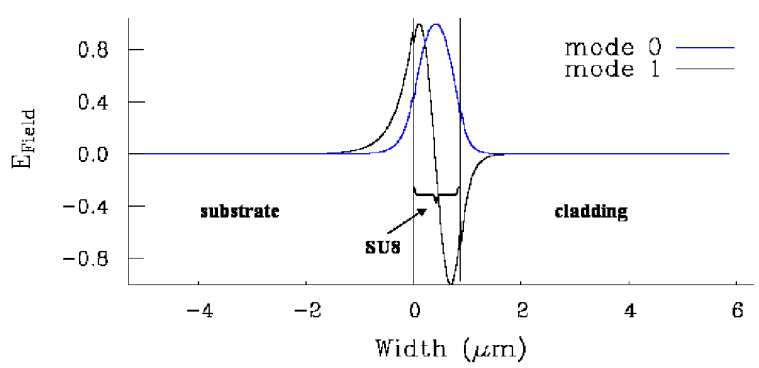

Fig. 10. Distribution of the field of TM polarization at a thickness of the waveguide layer $d_{\mathrm{SU}}=0.90 \mu \mathrm{m}$.

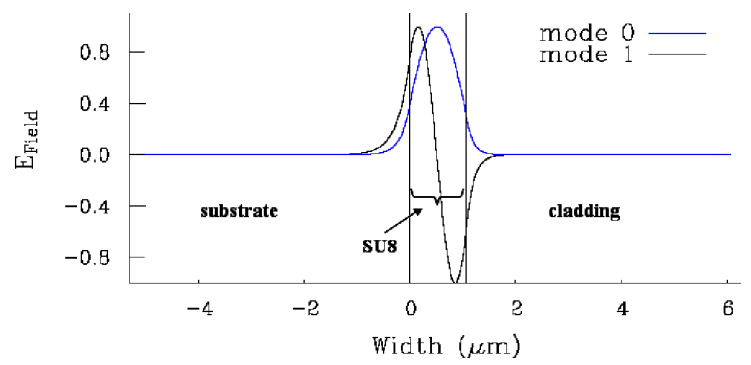

Fig. 11. Distribution of the field of TE polarization at a thickness of the waveguide layer $d_{\mathrm{SU} 8}=1.10 \mu \mathrm{m}$.

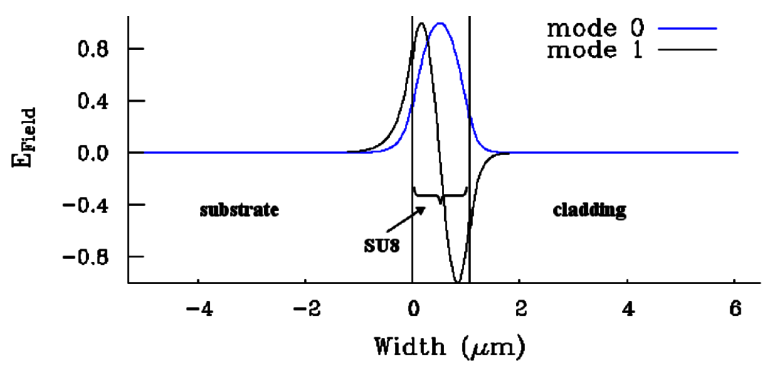

Fig. 12. Distribution of the field of TM polarization at a thickness of the waveguide layer $d_{\mathrm{SU} 8}=1.10 \mu \mathrm{m}$.

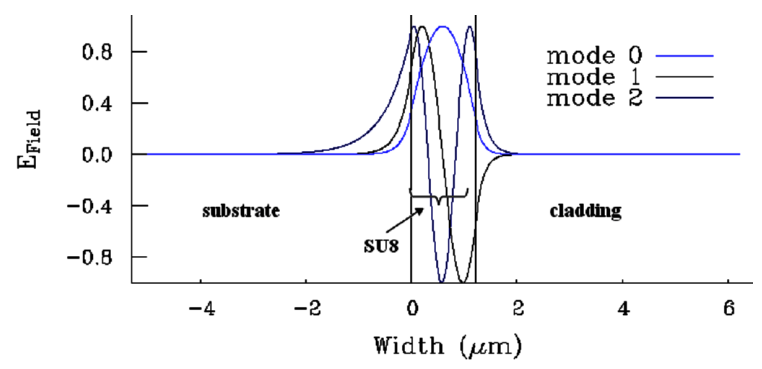

Fig. 13. Distribution of the field of TE polarization at a thickness of the waveguide layer $d_{\mathrm{SU} 8}=1.25 \mu \mathrm{m}$.

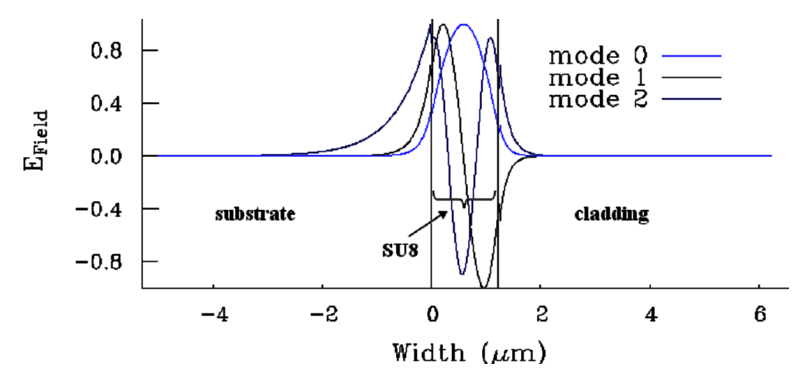

Fig. 14. Distribution of the field of TM polarization at a thickness of the waveguide layer $d_{\mathrm{SU} 8}=1.25 \mu \mathrm{m}$. 


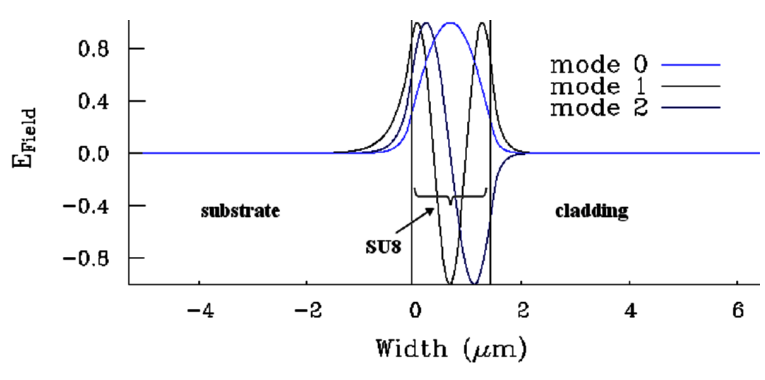

Fig. 15. Distribution of the field of TE polarization at a thickness of the waveguide layer $d_{\mathrm{SU} 8}=1.50 \mu \mathrm{m}$.

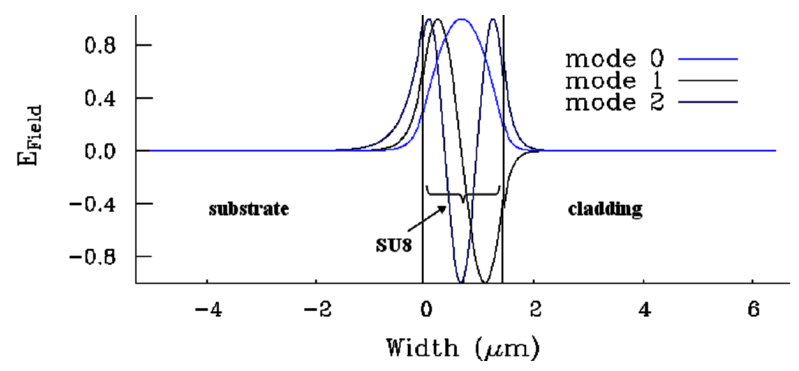

Fig. 16. Distribution of the field of TM polarization at a thickness of the waveguide layer $d_{\mathrm{SU} 8}=1.50 \mu \mathrm{m}$.

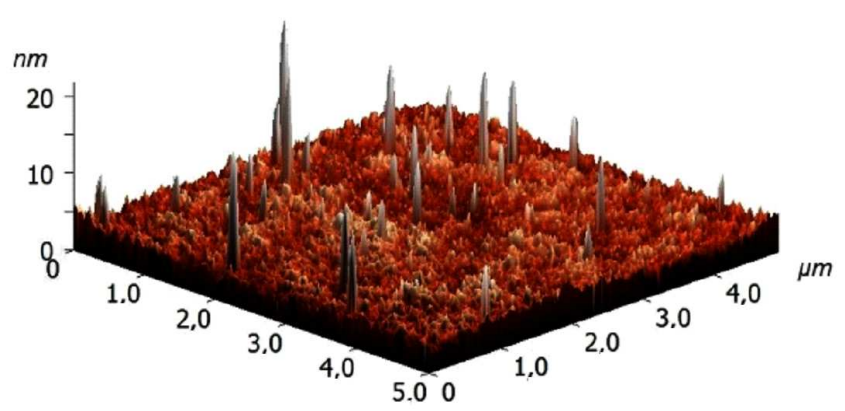

Fig. 17. Photo of a planar structure size $5 \times 5 \mu \mathrm{m}^{2}$ (velocity of spinning $v=4000$ rotations per minute).

Light propagating in the planar waveguide structure will penetrate deeper into that layer (substrate, cover) whose refractive index is more approximated to the waveguide layer [16]. Analyzing the presented distributions of the field, it can be perceived that in Figs. 14 and 15 the field of the modes $\mathrm{TE}_{2}$ and $\mathrm{TM}_{2}$ penetrates much deeper into the substrate layer than in the case of the order presented characteristics. In these cases the structure is characterized by a high sensitivity (Fig. 8 shows distinctly that this corresponds to the thickness of the waveguide displaying a high sensitivity $S\left\{n_{\mathrm{C}}\right\}$ in the modes $\mathrm{TE}_{2}$ and $\mathrm{TM}_{2}$ ). If the refractive index of the light in the cover layer were higher than in the substrate [19], the system might successfully operate as a sensor. Such a situation would be possible if between substrate and the

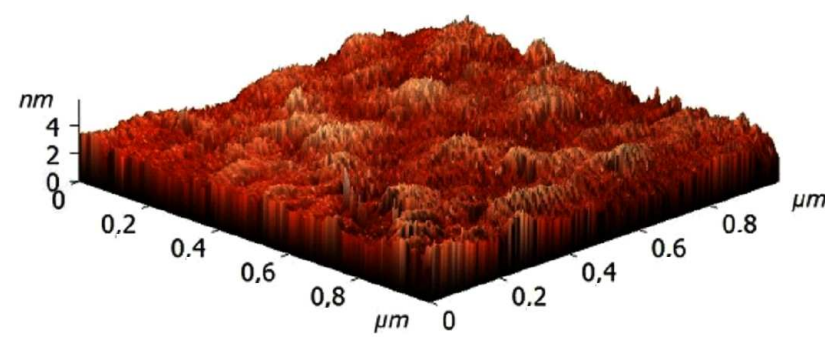

Fig. 18. Photo of a planar structure size $1 \times 1 \mu \mathrm{m}^{2}$ (velocity of spinning $v=4000$ rotations per minute).

SU8 layer there were a layer with the refractive index $n<1.33$ (a so-called reverse waveguide) [6, 20].

Figures 18 and 19 present exemplary images obtained while investigating the surface by means of a microscope of atomic forces AFM (the structure in the case of which the velocity of spinning in the course of the photolitography process amounted to 4000 rotations per minute). The rms of the investigated surface size $1 \times 1 \mu \mathrm{m}^{2}$ is $0.59 \mathrm{~nm}$.

The structures dealt with in this publication will be investigated in more detail in future, first of all measurements of their mode attenuation.

\section{Conclusion}

Investigation by means of an AFM microscope permitted to verify how much the velocity of spinning affects the obtained thickness of the waveguide layer. Applying the most proper velocity, a structure may be obtained displaying the highest sensitivity $S\left\{n_{\mathrm{C}}\right\}$ in relation to changes of the refractive index. This information is of much importance when a sensor of the evanescence field is being designed, applying the planar waveguide structure.

\section{Acknowledgments}

The work was sponsored by the State Committee for Scientific Research (NCBiR) within the grant N R01 034 06/2009.

\section{References}

[1] T. Pustelny, Physical and Technical Aspects of Optoelectronic Sensors, SUT Publisher Technology, Gliwice 2005.

[2] A. Sabac, C. Gorecki, M. Jozwik, L. Nieradko, C. Meunier, K. Gut, J. Eur. Op. Soc-Rapid. 2, 07026 (2007).

[3] K. Gut, Acta Phys. Pol. A 114, 121 (2008).

[4] A. Opilski, R. Rogoziński, K. Gut, M. Błahut, Z. Opilski, Opto-electron. Rev. 8, 117 (2000).

[5] T. Pustelny, K. Barczak, K. Gut, J. Wojcik, Opt. Appl. 34, 531 (2004). 
[6] K. Gut, S. Drewniak, Acta Phys. Pol. A 118, 1134 (2010).

[7] A. Szewczuk, M. Błahut, Acta Phys. Pol. A 118, 1254 (2010).

[8] P. Struk, T. Pustelny, K. Gut, K. Golaszewska, E. Kaminska, M. Ekielski, I. Pasternak, E. Łusakowska, A. Piotrowska, Acta Phys. Pol. A 116, 414 (2009).

[9] T. Pustelny, A. Oplski, B. Pustelny, Acta Phys. Pol. A 114, A-181 (2008).

[10] A. Szewczuk, M. Błahut, W. Pyka, Acta Phys. Pol. A 118, 1250 (2010).

[11] E. Maciak, Z. Opilski, T. Pustelny, M. Bednorz, J. Phys. IV (France) 129, 131 (2005).

[12] K. Gut, D. Nabagło, Acta Phys. Pol. A 116, 307 (2009).

[13] K.K. Hung, W.H. Wong, E.Y.B. Pun, Appl. Phys. A 80, $621(2005)$.
[14] K. Gut, T. Pustelny, D. Nabaglo, Acta Phys. Pol. A 118, 1136 (2010).

[15] T. Pustelny, M. Grabka, Acta Phys. Pol. A 116, 385 (2009).

[16] T. Pustelny, C. Tyszkiewicz, K. Barczak, Opt. Appl. 33, 469 (2004).

[17] T. Pustelny, E. Maciak, Z. Opilski, M. Bednorz, Opt. Appl. 37, 187 (2007).

[18] T. Pustelny, J. Ignac-Nowicka, Z. Opilski, Opt. Appl. 34, 563 (2004).

[19] R. Horvath, L.R. Lindvold, N.B. Larsen, Appl. Phys. B 74, 383 (2002).

[20] R. Horvath, H. Pedersen, Appl. Phys. Lett. 81, 2166 (2002). 